\title{
MATHEMATICAL MODELS \\ AND COMPUTER SIMULATIONS OF AERIAL SPRAYING AND DROPLETS DISTRIBUTION IN A TARGET SITE
}

\author{
Robert S. Rowiński \\ Polish Air Force Academy in Dęblin \\ Faculty of Aviation \\ ul. Dywizjonu 303, 08-521 Dęblin \\ r.s.rowinski@gmail.com
}

\begin{abstract}
Mathematical models describing aerial spraying and the distribution of liquid droplets on a target were presented. Relationships based on "free models" with Gaussian distribution of droplet concentrations and "bound models" that account for the impact of disturbances in the velocity field behind agricultural aircraft were expanded, and the hybrid model too. The results of experimental studies were presented and compared with theoretical calculations. The "bound model" was found to be the most effective solution for describing the physical phenomena that accompany the aerial spraying process.
\end{abstract}

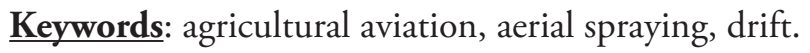

\section{SYMBOLS}

$\begin{array}{ll}A, a & - \text { coefficients } \\ b[\mathrm{~m}] & - \text { wing span } \\ d[\mu \mathrm{m}] & - \text { mean droplet diameter } \\ g\left[\mathrm{~m} \cdot \mathrm{s}^{-2}\right] & - \text { acceleration due to gravity } \\ b[\mathrm{~m}] & - \text { spraying height } \\ i & - \text { versor of } \mathrm{x} \text {-axis } \\ j & - \text { versor of } \mathrm{y} \text {-axis } \\ k & - \text { versor of } \mathrm{z} \text {-axis } \\ l & - \text { linear dimension }\end{array}$


$u^{*}\left[\mathrm{~m} \cdot \mathrm{s}^{-1}\right] \quad-$ friction velocity in boundary layer near the ground

$h^{*}[\mathrm{~m}] \quad-$ surface roughness parameter

$r[\mathrm{~m}] \quad-$ vector-radius in a plane perpendicular to flight direction

$r_{s}[\mathrm{~m}] \quad-$ propeller radius

$v\left[\mathrm{~m} \cdot \mathrm{s}^{-1}\right] \quad-$ air disturbance velocity relative to the ground

$v_{1}\left[\mathrm{~m} \cdot \mathrm{s}^{-1}\right] \quad-$ component of air disturbance velocity related to wing wake

$v_{2}\left[\mathrm{~m} \cdot \mathrm{s}^{-1}\right] \quad-$ component of air disturbance velocity related to propeller wake

$v_{3}\left[\mathrm{~m} \cdot \mathrm{s}^{-1}\right] \quad-$ wind speed

$t[\mathrm{~s}] \quad-$ time

$B_{V} \quad-$ cumulative droplet volume distribution

$C_{D} \quad-$ drag coefficient of droplets

$C_{V} \quad-$ coefficient of variation

$D\left[\mathrm{dm}^{3} \cdot \mathrm{ha}^{-1}\right] \quad-$ dose

I

- turbulence intensity

$K_{t} \quad-$ coefficient of turbulent diffusion

$N \quad$ - number of vortex lines modeling the wing wake

Pr $\quad-$ Prandtl number

[m] - vector-radius

$R[\mathrm{~m}] \quad-$ propeller wake radius

Re $\quad-$ Reynolds number

$T[\mathrm{~K}] \quad$ - temperature

$T[\mathrm{~N}] \quad-$ propeller thrust

$U_{*}\left[\mathrm{~m} \cdot \mathrm{s}^{-1}\right] \quad-$ dynamic velocity

$W\left[\mathrm{dm}^{3} \cdot \mathrm{s}^{-1}\right] \quad$ - flow rate

$V_{r}\left[\mathrm{~m} \cdot \mathrm{s}^{-1}\right] \quad-$ aircraft working velocity

$V\left[\mathrm{~m}^{3}\right] \quad$ - volume

$\alpha\left[^{\circ}\right] \quad-$ angle

$\Gamma\left[\mathrm{m}^{2} \cdot \mathrm{s}^{-1}\right] \quad$ - circulation

$\rho\left[\mathrm{kg} \cdot \mathrm{m}^{-3}\right] \quad-$ density

\section{Subscripts}

$o$

$-$

$\sim$

$c$

$d$

$p$
- initial

- average value

- influence of ground proximity

- liquid

- droplet

- air 


$\begin{array}{ll}r & - \text { working } \\ s & - \text { sedimentation } \\ u & - \text { crop field } \\ w & - \text { wind } \\ \left(^{*}\right) & -\mathrm{d} / \mathrm{dt}() \\ || & - \text { absolute value }\end{array}$

\section{INTRODUCTION}

Pesticide spraying plays a very important role in crop production. Chemical agents are highly effective in eliminating pests, diseases and weeds, and they are commonly applied due to relatively low cost. Beyer [4] summarized the view held by many experts that pesticides will continue to be widely applied in the $21^{\text {st }}$ century as one of the key factors in agricultural production that improve yield and crop quality. For those goals to be achieved, pesticides have to be continuously improved and, most importantly, farmers have to be educated about proper pesticide use.

From the 1950 s to the 1990 s, aircraft played an important role in chemical protection ${ }^{1}$ agriculture and forestry areas in the word. Airplanes and helicopters effectively protected crop fields and forests against pests and fires. They had a clear advantage over ground equipment due to higher effectiveness, lower cost per hectare and more even distribution of pesticides. Aircraft is indispensable in forest firefighting where rapid response to a detected threat is of essence. In France, the introduction of firefighting aircraft in 1980 decreased burned forest area 5.8-fold [21]. The area treated with the involvement of agricultural aircraft were for example in 1990 year: area F=390 mil. ha and the number of agricultural aircraft $\mathrm{N}=34000$. Statistical data relating to the share of fixed-wing and rotary-wing aircraft is not available.

Agricultural aircraft was widely applied in Poland. In 1975, treated area exceeded 1 million hectares per year, it increased to 2 million hectares in 1976 and 3 million hectares in 1977. In 1978-1984, agricultural aircraft was intensively used to fight the rapid increase in the population of the black arches moth (Lymantria monacha L) in Polish forests. In 1982, 160 airplanes and 21 helicopters were deployed to protect more than 2.5 million hectares of forests. [22]

Spray drift is one the key factors limiting the effectiveness and safety of aerial applications. Spray drift is the unintentional diffusion of pesticides and off-target contamination which can lead to:

1. damage or complete loss of neighboring crop fields, contamination of water bodies, recreational areas and urban areas. Those threats apply mostly to aerial application of herbicides which has been banned in Poland;

2. loss of sprayed substance,

3. possible decrease in crop yield due to the application of lower pesticide doses,

4. social conflict where non-experts criticize crop dusting programs in the media.

The above factors prompted scientific institutes dealing with aviation and the use of aircraft for crop and forest protection to develop theoretical analyses and conduct experiments investigating spray drift phenomena.

\footnotetext{
${ }^{1}$ Artificial fertilization, fire protection and pest control in crop fields and forests.
} 
From the scientific point of view, spray drift to off-target areas is a highly interesting phenomenon that has not been fully explored. It is difficult to describe mathematically because effective models should account for disturbances in the velocity field behind aircraft as well as the movement of droplets in a turbulent atmosphere where wind speed, air temperature and humidity influence droplet evaporation rates. The following issues should be addressed in attempts to solve the spray drift problem:

1. Identification and mathematical description of spray droplet motion and drift to off-target areas (crops fields, ground).

2. The application of research findings to improve agricultural aircraft design, and agricultural apparatus.

3. Determination of optimal conditions for aerial spraying and identification of buffer zones.

4. Competence of pilots.

\subsection{Objective}

The objective of this paper was to present mathematical models and computer simulations of physical phenomena responsible for the distribution and off-target drift of aerially applied spray droplets. Selected models were compared with experimental results to formulate proposals for future research.

\subsection{Movement of spray droplets}

The motion of spray droplets dispensed by nozzles can be divided into four phases:

Phase I - droplets move at high speed which is set by the nozzles and drift velocity of aircraft. This phase is very short due to high drag;

Phase II - droplets fall with sedimentation velocity (terminal velocity) which is affected by disturbances in the velocity field behind aircraft and movement droplets with air masses (wind, turbulence, convection);

Phase III - takes place when the disturbances caused by the aircraft subside. Droplets which are still in the air are subjected to forces of gravity, aerodynamic drag and movement of air masses;

Phase IV - droplets penetrate the crop field by settlement, reflection and runoff.

\section{MODELING DROPLET MOTION AND DISTRIBUTION}

There are two types of models that illustrate the motion and distribution of droplets:

1. models that do not account for the influence of disturbances in the velocity field behind aircraft on droplet motion and distribution;

2. models that do account for the above factor as well as other parameters that affect droplet trajectory and distribution and the method presented as AGDISP, which is currently North American Standard.

The above models are referred to as "free models" and "bound models", respectively. The described processes can also be analyzed with the involvement of mathematical statistics based on the results of experiments and practical applications. [15] 


\subsection{Free models}

In a free model, sprayed liquid is regarded as a cloud of droplets which are subjected to forces of gravity, vertical turbulent fluctuations and wind forces acting parallel or perpendicular to the direction of flight.

A semi-empirical model was developed by [3], it was further modified and expanded by [21] who modified droplet concentration formula and accounted for droplet evaporation [8]. KAUL, ET.AL. [I 5] used the model presented [19] to determine droplet evaporation rates and relied on the findings of [28] to calculate droplet drift .

Assumptions:

1. In a spray cloud, droplet concentrations have Gaussian distribution with standard deviation $\sigma_{\mathrm{y}}$ along the $y$-axis in the direction of wind and standard deviation $\sigma_{z}$ relative to the vertical $z$-axis. The external boundary of the cloud is an area where droplet concentrations decrease to $10 \%$ of their maximum values. On this assumption, the physical size of a cloud is $4.3 \sigma_{y}$ and $4.3 \sigma_{z}$ [3], Fig. 1. The cloud becomes dispersed due to sedimentation, turbulence and wind motion. Experimental data indicates that the dispersion process is linear at initial and successive stages.

2. Droplets are small where $V t h<<\sigma^{2}$, implying that sedimentation velocity is low.

3. Average wind speed $V_{w}$ and the coefficient of turbulent diffusion $K_{t}$ remain constant with changes in height.

4. All droplets leave the cloud when it reaches the top of the crop field and penetrates it. At this level, droplet concentrations in air equals zero, i.e. $\phi=0$ for $z=h_{u}=0$, which represents the boundary condition.

The volume flux of droplets falling due to gravity at sendimentation velocity $\mathrm{V}_{s}$ per unit of area can be described by the below formula:

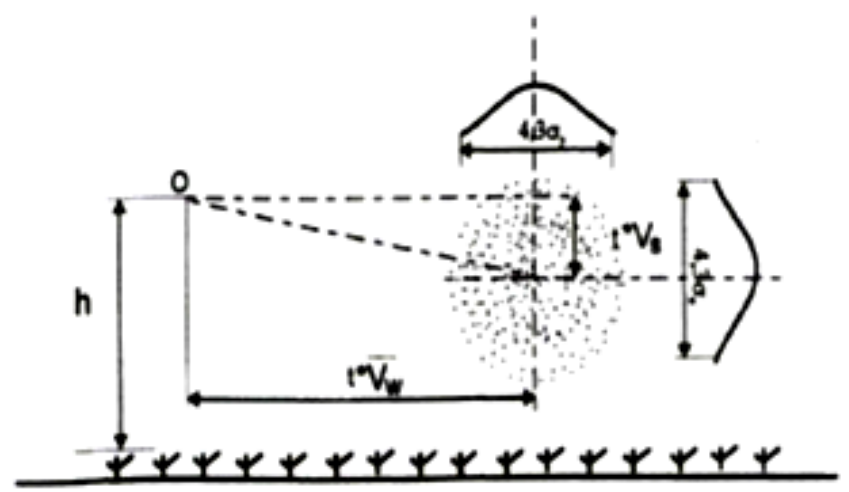

Fig. 1. Model of the Gaussian distribution [3]

$$
W_{s}=V_{s} \phi(y, z, t)_{z=h_{u}}
$$

The flux affected by vertical turbulence takes on the following form: 


$$
W_{t}=K_{t}\left(\frac{\partial \phi}{\partial z}\right)_{z=h_{u}}
$$

where: $\left(\frac{\partial \phi}{\partial z}\right)_{z=h_{u}}$ - vertical concentration gradient at the top layer of the crop field, i.e. $\Phi=0$ for $z=h_{u}=0$

Total flux:

$$
W=W_{s}+W_{t}=V_{s} \phi(y, z, t)_{z=h_{u}}+K_{t}\left(\frac{\partial \phi}{\partial z}\right)_{z=h_{u}}
$$

concentration function: $\Phi(\mathrm{y}, \mathrm{z}, \mathrm{t})[8]$, can be modified as follows:

$$
\phi=\frac{1}{\sqrt{2 \pi}} \frac{W^{\prime}}{V_{r} \sigma} \exp \left\{\frac{-2 V_{S}(z-h) t-V_{S}^{2} t^{2}}{2 \sigma^{2}}\right\}\left\{\exp \left[\frac{(z-h)^{2}}{2 \sigma^{2}}\right]-\exp \left[\frac{-(z+h)^{2}}{2 \sigma^{2}}\right]\right\}
$$

where: $W^{\prime}$ - flow rate relative to average wind speed

$$
t=\frac{y}{\overline{V_{w}}}
$$

In view of point 2 above, it can be assumed that:

$\sigma \sim \mathrm{y}$ and $\sigma=\mathrm{I} \cdot \mathrm{y}$

where:

$$
I=\frac{\sqrt{\overline{w^{2}}}}{\overline{V_{w}}} \cong \frac{U_{*}}{\overline{V_{w}}}
$$

Coefficient of turbulent diffusion $K_{t}$ can be determined with the use of the below formula:

$$
K_{t}=U_{*}^{2} t
$$

Equations (5) and (6) are deployed to produce:

$$
K_{t}=I^{2} \overline{V_{w}} y
$$

Concentration function $\varphi$ is differentiated relative to z, where $\Phi=0$ for $z=h_{u}=0$. The above dependencies are modified, rearranged and related to the area of one hectare to determine the spray dose:

$$
D=\sqrt{\frac{2}{\phi}} 10^{3} \frac{h W}{I V_{r} y^{2}} \exp \left[-\frac{1}{2 I^{2}}\left(\frac{h}{y}-\frac{V_{s}}{V_{w}}\right)^{2}\right]
$$

The distribution described by formula (9) is shown in Fig. 2. Maximum dose $\mathrm{D}_{\max }$ is determined for $y_{D \max }$. After modification, the value of $y_{D \max }$ can be described with the use of the following equation: 


$$
y_{D_{\max }}=0.25 \frac{h T}{I}\left(\left(\frac{8}{T^{2}}+1\right)^{0.5}-1\right)
$$

For large droplets at $I \rightarrow 0$, when sedimentation velocity is greater than turbulence:

$$
y_{D_{\max }}=l \frac{h \overline{V_{w}}}{V_{S}}
$$

For small droplets or strong turbulence:

$$
y_{D_{\max }}=\frac{h \overline{V_{w}}}{\sqrt{2} U_{*}}=\frac{h}{\sqrt{2} I}
$$

Based on the given range of droplet sizes of $100 \mu \mathrm{m} \leq 800 \mu \mathrm{m}$ [21], their sedimentation velocity can be expressed by a linear function of droplet diameters:

$$
V_{s}=a_{0}+a_{1} d
$$

where: $\mathrm{a}_{\mathrm{o}}=-0.3126, \mathrm{a}_{1}=5.3 \cdot 10^{3}$ with correlation coefficient $\mathrm{r}=0.990$.

Formula (13) is substituted into equation (9) to produce:

$$
D_{1}=\sqrt{\frac{2}{\pi}} 10^{3} \frac{h W}{I V_{r} y^{2}} \exp \left[-\frac{1}{2 I^{2}}\left(\frac{h}{y}-\frac{a_{0}+a_{1} d}{\overline{V_{w}}}\right)^{2}\right]
$$

The above formula can be used to determine dose distributions, but we do not take into account droplet evaporation. We can make the analysis of this process by including into equation (14) relation $\mathrm{d}$ in the form;

$$
\mathrm{d}=\mathrm{Ad} \mathrm{d}_{\mathrm{o}}\left(\mathrm{y} / \mathrm{V}_{\mathrm{w}}\right)^{\mathrm{Al}}
$$

where: $A, A_{1}$ - empirical coefficients received from experiment, depending on the nozzles type and liquid formulation [21].

$$
D_{2}=\sqrt{\frac{2}{\pi}} 10^{3} \frac{h W}{I V_{r} y^{2}} \exp \left[-\frac{1}{2 I^{2}}\left(\frac{h}{y}-\frac{a_{0}+a_{1} A d o\left(\frac{y}{V w}\right) A 1}{\overline{V_{w}}}\right)^{2}\right]
$$

It is also possible, to compare, of droplets evaporation use relation proposed by [32]:

$$
d=\left[d_{0}^{2}-84.76 * 10^{-12}(1+0.27 \sqrt{R e)} \Delta T t)\right]^{0.5}
$$


Formula (17) was substituted into equation (14) to produce:

$$
D_{3}=\sqrt{\frac{2}{\pi}} 10^{3} \frac{h W}{I V_{r} y^{2}} \exp \left[-\frac{1}{2 I^{2}}\left(\frac{h}{y}-\frac{\left.a_{0}+a_{1}\left[d_{0}^{2}-84.76 * 10^{-12}(1+0.27 \sqrt{R e}) \Delta T \frac{y}{\overline{V_{w}}}\right)\right]^{0.5}}{\overline{V_{w}}}\right)^{2}\right]
$$

The discussed models (Fig.2) conforms to experimental data (Fig. 7), but due to the adopted assumptions, it seems to be more suited for analyses of pollutant distribution from industrial facilities than droplet distribution in aerial applications.

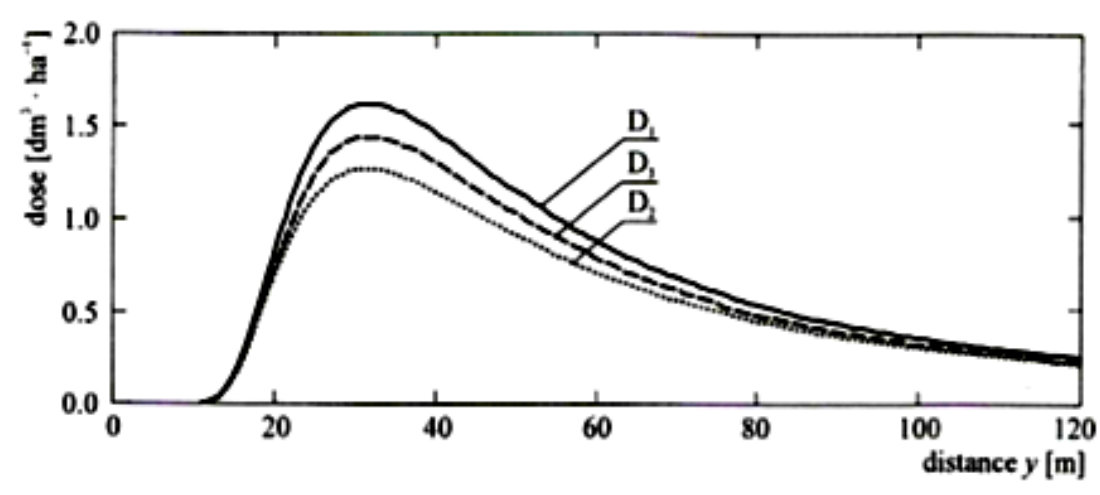

Fig. 2. The influence of evaporation on mass distribution.h $=5 \mathrm{~m}, \mathrm{~W}=3 \mathrm{dm}^{3} / \mathrm{s}, \mathrm{d}_{0=} 80 \mu \mathrm{m}$,

$$
\mathrm{V}_{\mathrm{w}}=3.5 \mathrm{~m} / \mathrm{s}, \mathrm{V}_{\mathrm{r}} \mathrm{m} / \mathrm{s}[23]
$$

\subsection{Bound models}

The flight of aircraft causes velocity field disturbances across a significant area of the flight path. The energy of such disturbances is immense, and there have been cases where a small airplane was thrown off the take-off lane because it had started taxiing too early after the departure of large passenger aircraft. The above is caused by wingtip vortices, the arrangement of tail control surfaces, propeller wake and trails of exhaust gas from jet engines or turboprop engines. At further distance behind an airplane or a helicopter, vortices are concentrated in two sites whose axes are separated by a distance equal to approximately 0.8 of wing span (Fig. 3).

The effect of disturbance energy on the trajectory of droplets sprayed with the speed of $8-12 \mathrm{~m} \cdot \mathrm{s}^{-1}$ has to be taken into account. Trajectory will be determined mostly by droplet size and the location of nozzles on the spraying boom.

The effect of disturbances on the motion and distribution of droplets was first described by Reed in a NACA report of 1954 [20].

Reed analyzed droplet trajectory in plane perpendicular to the direction of flight on the assumption that droplets move in a velocity field induced by free vortices modeled as two infinitely long vortex lines which interact mutually over time. The above author assumed that droplet spectra have normal distribution. 


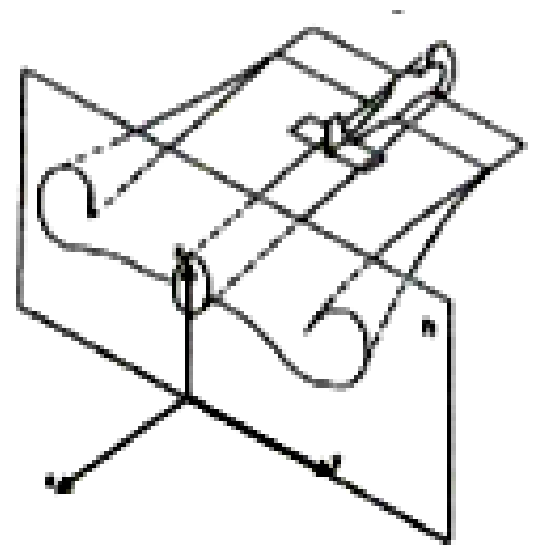

Fig. 3. Auxiliary plane $\pi$ for determining the deformation of the vortex behind the aircraft. [18]

He optimized the location of nozzles to optimize the effective swath width. Derevianko [9] and KAMIŃSKI [I4] expanded the above theory in studies involving biplanes. They examined two pairs of horseshoe vortices and the effects exerted by propeller wake and crosswind. KAMIŃsKi [I4] and [32] analyzed the influence of droplet evaporation. The above problems were also addressed by other researchers [5], [7], [19], [26], [30], [31], [32].

The model proposed by Pietruszka[i 8] seems to best describe droplet dispersion and distribution. The above model was formulated on the following assumptions:

1. a velocity disturbance field behind aircraft is generated by vortex wake shed by wings and the propeller. The wing wake is modeled by inviscid and incompressible flow of 20 vortex line,

2. an additional velocity field generated by a vortex shed by the propeller axis and a thin vortex shed by propeller circumference may be observed in the propeller wake. Vortex displacement from propeller axis and deformation of the propeller wake due to wing interference were taken into account,

3. the velocity field is additionally modified by the influence of ground proximity,

4. droplet evaporation rates have been taken into account,

5. the logarithmic wind velocity profile near the ground is determined by the height of crop plants.

Two separate problems were modeled:

1. the velocity field behind aircraft,

2. movement of droplets in a given area of the velocity field.

\section{VELOCITY FIELD BEHIND AIRCRAFT}

A velocity disturbance field behind aircraft is the vector sum of wing wake velocity, propeller wake velocity and wind speed:

$$
\vec{v}=\overrightarrow{v_{1}}+\overrightarrow{v_{2}}+\overrightarrow{v_{3}}
$$




\subsection{Wing wake}

The wing is a lifting surface [1] in incompressible, stationary potential flow that stretches to fuselage surface. Wing-fuselage interferences are analyzed based on the slender-body theory formulated in [1]. The distribution of vortex line circulations was determined by the "vortex lattice" method proposed by [16].

Deformations of vortex lines in a plane perpendicular to the direction of flight are presented in Fig.3. The initial configuration of vortex lines is related to the wing lifting line. The movement of vortex lines in plane $\Pi$ is described by the following formula:

$$
V_{r}=\frac{\partial \vec{r}}{\partial x}=\dot{\vec{r}}
$$

where: $r$ - velocity vector of the $\mathrm{i}^{\text {th }}$ vortex line perpendicular to the direction of flight.

The effect of singularities on the fuselage is induced by mutual interactions between vortex lines, and it rapidly disappears. This phenomenon can be illustrated with the below equation:

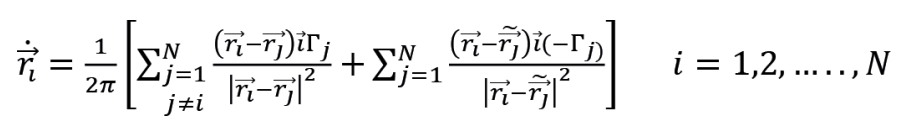

where: $\Gamma_{j}$ is the circulation of the $\mathrm{j}^{\text {th }}$ vortex line.

The above set of differential equations is solved by numerical integration.

Assuming that velocity field disturbances in the vicinity of aircraft result from vortex wake generated by horseshoe vortices, and more remote disturbances - by vortex lines, disturbance velocity can be modeled with the below equation:

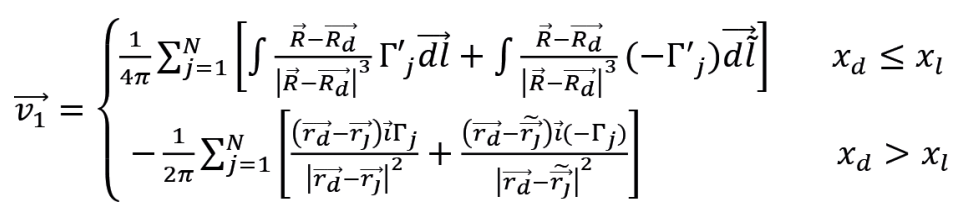

where: $\Gamma_{j}^{\prime}$ is the circulation of the $j^{\text {th }}$ horseshoe vortex, $d l$ - component of a horseshoe vortex, $x_{d}-$ distance between the droplet and aircraft on the $\mathrm{x}$-axis.

The influence of ground proximity was determined by mirror reflection.

\subsection{Propeller wake}

A rotating propeller induces an additional velocity field behind it. This field can be expressed by the below formula:

$\omega$

$$
\overrightarrow{v_{2}}=\frac{\Gamma_{s}}{4 \pi}\left[\vec{\imath} \frac{-\omega}{v_{r}}+\vec{\jmath} \frac{-z^{\prime}}{y \prime^{2}+z \prime^{2}}+\vec{k} \frac{y \prime}{y^{\prime 2}+z \prime^{2}}\right]\left[1+\sin \left(r_{s}^{2}-y^{\prime 2}-z^{\prime 2}\right)\right]
$$


where: $\Gamma_{s}=2 \mathrm{M} / \rho_{\mathrm{a}} \omega \mathrm{R}^{2}$ is the circulation of the vortex inside the propeller axis

$\omega$ - angular velocity of the propeller,

y' z' - coordinates of $r_{d}-r_{s}$,

$r$ - vector-radius at the center of propeller wake cross-section,

$r_{d}-$ vector-radius of droplet position in a plane perpendicular to the direction of flight.

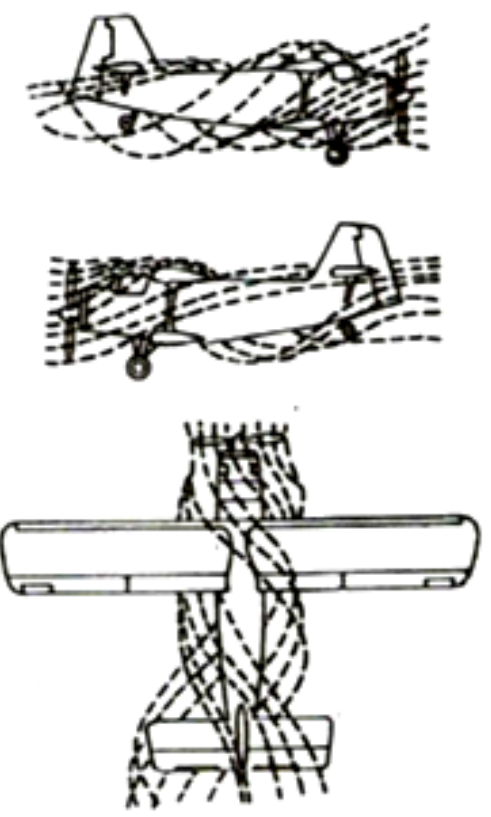

Fig.4. Propeller wake

In propeller wake theory, $\mathrm{r}_{\mathrm{s} \pi}$ is given by the below formula:

$$
\mathrm{r}_{\mathrm{s}}=\left(\mathrm{V}+\Gamma \mathrm{s} \omega / 4 \pi \mathrm{V}_{\mathrm{r}}\right) /\left(\mathrm{V}+\Gamma_{\mathrm{s}} \omega / 2 \pi \mathrm{V}_{\mathrm{r}}\right)
$$

The effect of propeller wake (Fig.4) on the velocity field on the wing and fuselage is taken into account by modifying boundary conditions on the fuselage and the wing section influenced by propeller wake.

Propeller wake becomes displaced with distance from aircraft. g. 6). Its displacement is described by the following formula:

$$
V_{r} \frac{\partial \overrightarrow{r_{s}}}{\partial x}=\dot{\overrightarrow{r_{s}}}
$$

\subsection{Wind speed}

Average wing speed at flight height $h$ has been adopted for calculations. In determinations of the coefficient of variation of effective swath width, which is one of the key determinants of treatment quality, it is assumed that wind direction is parallel to the flight direction vector with a reverse sense. 
In determinations of droplet drift, wind direction is assumed to be perpendicular to the direction of flight.

The influence of ground coverage (type of crop) on the velocity field was determined by introducing a boundary layer with a logarithmic velocity profile [11]:

$$
\overrightarrow{v_{3}}=\frac{U_{*}}{k} \ln \left(\frac{h}{h_{*}}\right)
$$

where: $k$ - von Karman constant.

\section{DROPLET MOTION}

\subsection{Motion equation}

Droplets sprayed with high initial speed are characterized by significant differences in diameter from below $100 \mu \mathrm{m}$ to several hundred micrometers, subject to nozzle type. The respective Reynolds numbers were in the range of $0.1 \leq \mathrm{Re} \leq 100$ relative to sedimentation velocity.

According to [6], the correlation between the droplet drag coefficient and Reynolds number is represented by the below formula:

$$
C_{D}=\left\{\begin{array}{lr}
0.455 & R e \geq 900 \\
\frac{24}{R e}\left(1+0,15 R e^{0.687}\right) & 0.5<R e<900 \\
\frac{24}{R e}+4.5 & R e \leq 0.5
\end{array}\right.
$$

The approximation error does not exceed 6\% for this range of Reynolds numbers. Droplet motion can be expressed by the following general formula [27]:

$$
\frac{d}{d t}\left(m \dot{\overrightarrow{R_{d}}}\right)=m \vec{g}+\overrightarrow{F_{D}}+\overrightarrow{F_{A}}+\overrightarrow{F_{M}}+\overrightarrow{F_{B}}
$$

where:

$\mathrm{m}=\pi \rho_{\mathrm{d}} \mathrm{d}^{3} / 6$

$F_{D}$ - aerodynamic drag,

$F_{A}$ - effect of apparent air mass,

$F_{M P} F_{B}-$ Magnus and Basset forces, respectively.

In the analyzed form of motion, $F_{A^{\prime}}, F_{M^{P}} F_{B}$ can be disregarded. Droplet evaporation rates are taken into account based on the formula proposed by [19] which is consistent with experimental results for $\operatorname{Re} \leq 200$. The above mentioned equation has the following form:

$$
d=-\frac{A}{2 d_{0}}\left(1+0.3 \operatorname{Pr}^{\frac{1}{3}} \operatorname{Re}^{\frac{1}{2}}\right) \Delta T
$$

where: $A=82.47510^{-12} \mathrm{~m}^{2} \cdot \mathrm{K}^{-1} \cdot \mathrm{s}^{-1}$ 
The droplet motion equation takes on the following form:

$$
\ddot{\overrightarrow{R_{d}}}=\vec{g}-\frac{3}{4} C_{D} \frac{\rho_{a}\left|\dot{\overrightarrow{R_{d}}}-\vec{v}\right|\left(\dot{\overrightarrow{R_{d}}}-\vec{v}\right)}{\rho_{d} d}
$$

where: $d=d(t)$ and $\rho_{d}=\rho_{d}\left(\mathrm{~d} / \mathrm{d}_{0}\right)$

\subsection{Trajectory and distribution of droplets}

REED [20] presented the correlation between droplet spectra, droplet trajectories and their lateral distribution on a crop field. Let us assume that the active substance in the sprayed liquid does not evaporate. It is also assumed that $y_{g}=y_{g}\left(d_{o}\right)$, where $y_{g}$ is coordinate $y$ of a drop with initial diameter $d_{o}$ falling on a crop field, the sprayed substance is released by point emission, and $B_{v}=B_{v}(d)$ is cumulative droplet volume distribution. Under the given conditions, the dose can be calculated from the following formula:

$$
\bar{D}=\frac{W}{V_{r}}\left|\frac{B_{v}\left(d_{0}+\Delta d\right)-B_{v}\left(d_{0}\right)}{y_{g}\left(d_{0}+\Delta d\right)-y_{g}\left(d_{0}\right)}\right|
$$

$D$ is the average dose of the active ingredient on the ground in strip $\left\langle y_{g}\left(d_{o}+\Delta \mathrm{d}\right)-y_{g}\left(d_{0}\right)>\right.$ in terms of liquid volume of the initial dose, and:

$$
D_{0}=\frac{W}{V_{r}}\left|\frac{\frac{d B_{v}}{d(d)}\left(d_{0}\right)}{\frac{d y_{g}}{d(d)}\left(d_{0}\right)}\right|
$$

where: $D_{o}-$ local dose for $y_{g}(d)$.

When droplets are sprayed by many nozzles, the dose (both local and average) is the sum of doses for all nozzles. Droplets within the propeller wake are treated differently. This highly turbulent flux affects droplet trajectory, it moves droplets to the other side and disrupts distribution symmetry.

According to [18], the calculation process can be divided into four stages for greater convenience:

1. determination of span-wise distribution of circulation,

2. determination of vortex wake deformation behind aircraft,

3. solution of the droplet motion equation,

4. determination of spray distribution.

\section{COMPUTATIONAL MODEL}

\subsection{Free model}

A computer simulation of the "free model" was performed based on the following input data: flight parameters, flow rate, average droplet diameter, evaporation rate and turbulence intensity. Theoretical and experimental data regarding dose distribution as a function of drift is presented in Fig. 5. and Fig. 6. 


\subsection{Bound models}

The bound model supported an in-depth analysis of the discussed problem.

The first step in the procedure involved the determination of the span-wise distribution of circulation. Vortex wake wrapping $(t=0 \mathrm{~s})$ and vortices $46.4 \mathrm{~m}$ behind the trailing edge $(t=1 \mathrm{~s})$ and $185.6 \mathrm{~m}$ behind the trailing edge $(t=4 \mathrm{~s})$ were calculated in a plane perpendicular to the direction of flight. The result of calculation process is presented in Fig. 5.

The mathematical model supported analyses of droplet trajectory in a plane perpendicular to the direction of flight, subject to droplets size and nozzle distribution on the spraying boom. The trajectories of droplets with diameter of $150 \mu \mathrm{m}, 200 \mu \mathrm{m}$ and $300 \mu \mathrm{m}$ are presented in Fig. 6.
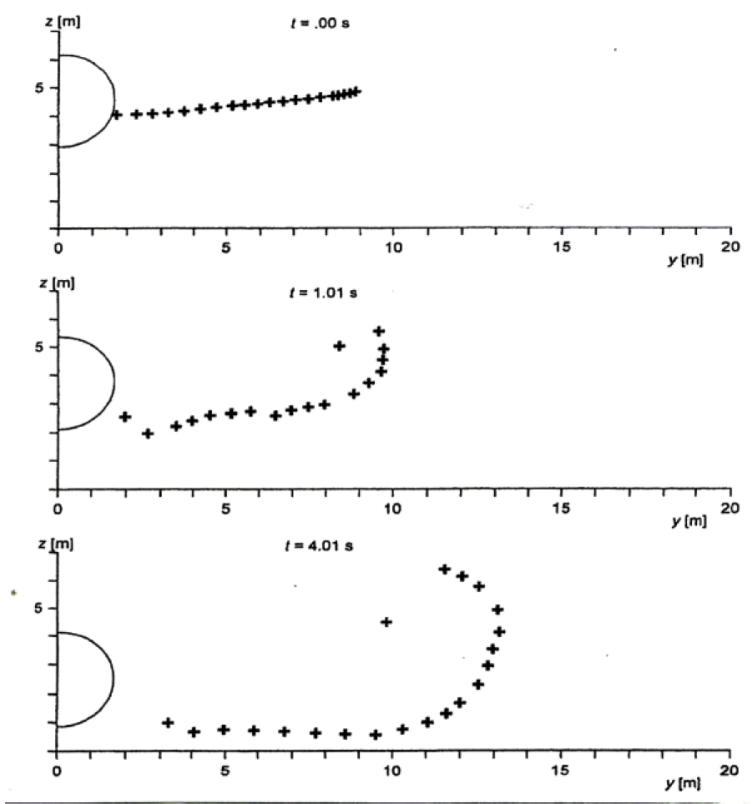

Fig.5. Cross-section vortex wake behind the aircraft (PZL M18 “Dromader”).[18]

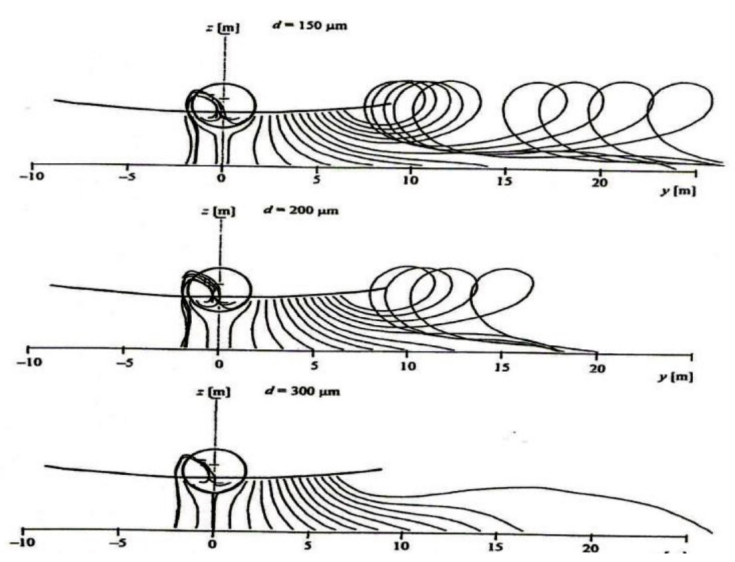

Fig.6. Trajectories of water droplets [21] 
The conclusion of this analysis is fig.7. present distribution received by Pietruszka [18], Trayford [32] and experimentally

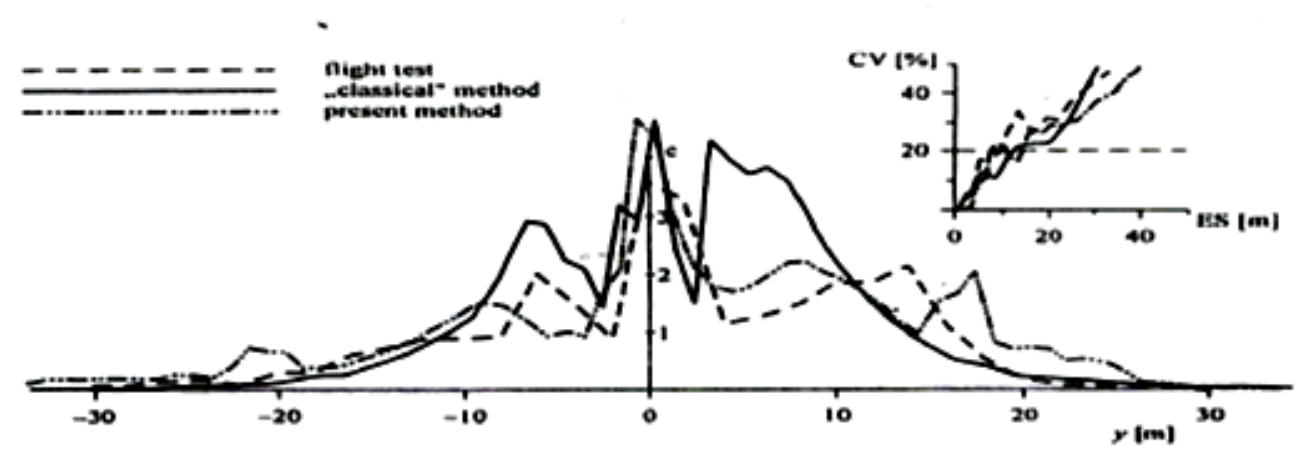

Fig.7. Lateral distribution of 1\% nigrosine aqueous solution determined theoretically and experimentally [18], compare with proposed by [32].

Experiment with involvement of the M-18 "Dromader", airplanes equipped with jet nozzles of flow rate $\mathrm{W}=7.1 \mathrm{dm}^{3} / \mathrm{s}, \mathrm{d}_{\mathrm{MV}}=215 \mu \mathrm{m}$ and parameters of flight: $\mathrm{h}=4 \mathrm{~m}, \mathrm{Vr}=46,4 \mathrm{~m} / \mathrm{s}$, winter speed $\mathrm{VW}=0.2 \mathrm{~m} / \mathrm{s}$

\subsection{The Agricultural Dispersal model (AGDISP)}

It is interesting and popular model which is the currently North American Standard. The model was presented first time by Bilianin et. al [5 ] in 1989 year and modified several times by Teske and Teske et.al, for example [30], [31]. In their opinion the speed of rotation in aerodynamical wake can be expressed with a simple two-dimensional flow field. The form of this field, size and chracter od drift depend to a large extend on the size of the aircraft.

If we discussed flow field, the model can present too large simplifications:

1. The model makes an assumption that all aerodynamical lift which is generated by wings is only the sole sources of disturbances flow field around the aircraft.

2. Agrees with vortex lattice method (VLM), a plane can be substitute of field of vortex. In AGDISP method the wing wake is modelling the flow with only one horseshoe vortex which exists in a moment when a flow passed the plane, in[18] is 20 .

3. The formula of circulation of this wire for airplanes and specially for helicopters is too large of simplification.

4. Propeller wake model is made on assumption that speed of vortex generated by propeller is proportional to the radius of a propeller $(\mathrm{R})$ and achieves maximum for $\mathrm{R}$. Above is equal to zero. It is not correct.

In Seredyn's opinion [26] AGDISP presents the problem of aerial spraying worse than Pietruszka's [18] model. 


\section{EXPERIMENTAL INVESTIGATION}

The Institute of Agricultural Aviation at the former University of Agriculture and Technology in Olsztyn conducted extensive research into spray drift at Germany old an airport in Gryźliny near Olsztyn. The field has the area of more than 100 ha, and it is covered with grass. The applied methodology was described in detail in [24].

Two types of aircraft were used: An-2R airplane and Mi-2R helicopter.

Table 1.Technical parameters of tests

\begin{tabular}{|c|c|c|c|c|c|c|}
\hline Aircrafts & Apparatus & Nozzles & Dose [1/ha] & $\operatorname{dmv}[\mu \mathrm{m}]$ & $\mathrm{V}[\mathrm{m} / \mathrm{s}]$ & $h[\mathbf{m}]$ \\
\hline \multirow[t]{3}{*}{ An -2R } & atomizers & AU-3000 & 9.65 & 109.9 & 44.4 & 4.5 \\
\hline & jet nozzle & W -7.2 & 48.35 & 186.1 & 44.4 & 4.5 \\
\hline & jet nozzle & $\mathrm{W}-17.4$ & 106.16 & 223.2 & 44.4 & 4.5 \\
\hline \multirow[t]{2}{*}{ Helicopter } & atomizer. & electrical & 8.08 & 93.6 & 22.2 & 4.5 \\
\hline & atomizer & electrical & 20.50 & 125.6 & & 4.5 \\
\hline
\end{tabular}

The following parameters were registered: height of flight, flight speed, aircraft position relative to the measurement line, weather conditions, wind speed, wind direction, air temperature and air humidity at the altitude of $2 \mathrm{~m}$. Two spray solutions were applied'

$-2 \%$ aqueous solution of nigrosine,

$-30 \%$ aqueous solution of nitrogen with the addition of $2 \%$ nigrosine.

The applied liquids were models of aqueous solutions and liquid fertilizers which are applied in practice. The measurement line was parallel to wind direction, and it comprised the following sampling sites:

- measurements of mass distribution along a section of $200 \mathrm{~m}$,

- measurements of droplet size and spraying density along a section of $800 \mathrm{~m}$,

- three masts with the height of $8 \mathrm{~m}$ positioned at the distance of $100 \mathrm{~m}, 300 \mathrm{~m}$ and $500 \mathrm{~m}$ from the flight axis. The measurement line is presented in Fig. 8.

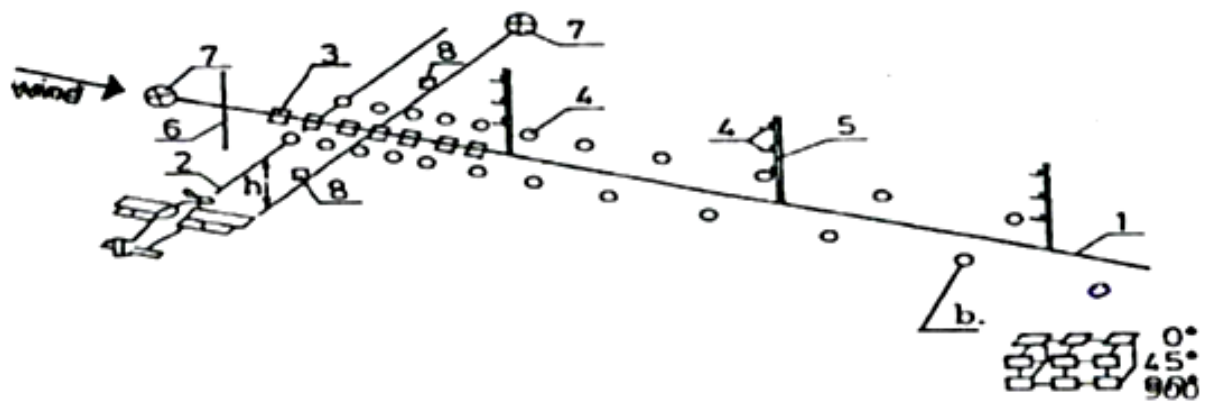

Fig.8. Measurement line. (1. measurement line, 2.fight path, 3.mass samplers, 4.droplet samplers, 5.masts, 6.measurement of meteorological conditions, 7.cameras, 8.markers.) [23] 
Following the deposition of the sprayed liquid, the samples were collected and analyzed calorimetrically to determine substance mass. The size of droplet traces was determined with the use of a computer-aided imaging system in The Institute of Aviation in Warszawa. Every test was performed in 3 to 5 replications. The above experiment was discussed also in [23], [25]. The theoretical and the experimental distribution is presented in Fig.9

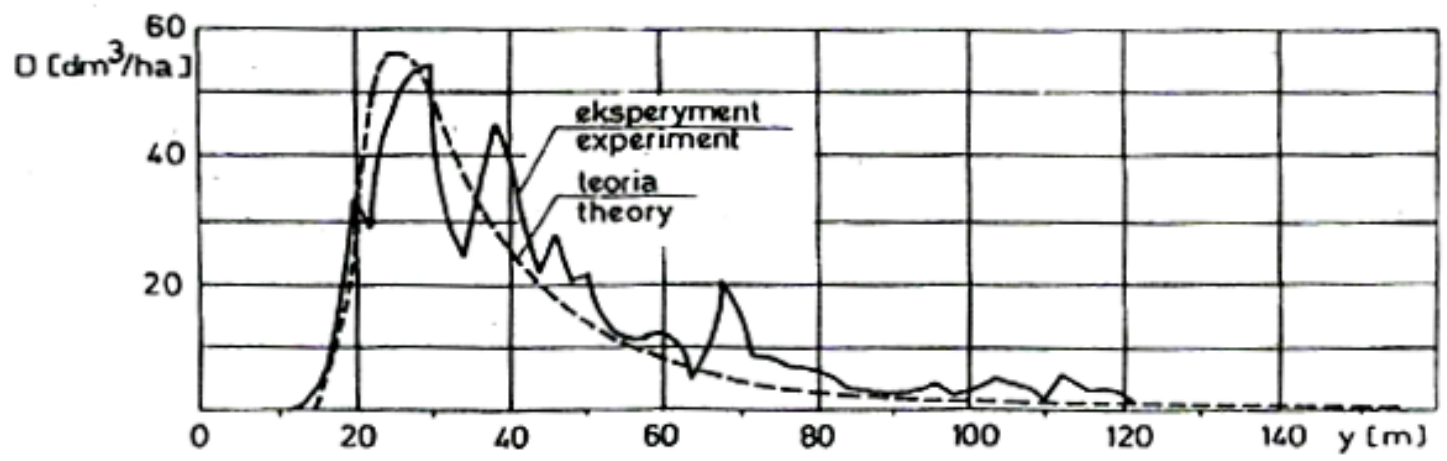

Fig.9. Comparison of theoretical and experimental results. $D=48.35 \mathrm{dm}^{3} / \mathrm{ha}, \mathrm{W}=7.35 \mathrm{dm}^{3} / \mathrm{s}, \mathrm{Vr}=44.4 \mathrm{~m} / \mathrm{s}$, $\mathrm{Vw}=4.5 \mathrm{~m} / \mathrm{s}, \mathrm{h}=4.5 \mathrm{~m}, \mathrm{Vw}_{=} 4.5 \mathrm{~m} / \mathrm{s}, \mathrm{I}=0.1, \mathrm{~d}_{\mathrm{VM}}=187 \mu \mathrm{m}[21]$

\section{CONCLUSIONS}

1. Bound models, in particular the expanded model proposed by [18] support analyses of physical phenomena that accompany the movement and distribution of aerially sprayed droplets. The modeled results are highly consistent with experimental data.

2. Bound models have significant practical implications. They provide a low-cost alternative to field experiments aiming to optimize the lateral distribution of the sprayed droplets (low coefficient of variation) and the distribution of nozzles on the boom.

3. Free models are also characterized by a high degree of consistency with experimental data, they are simple to use, but they fail to explain all physical phenomena that accompany the spraying process.

4. The reliability of free models could be improved by abandoning certain computational simplifications, in particular constant values of wind speed and coefficients of turbulent diffusion.

5. Further research is needed to produce a higher degree of conformity between theoretical and experimental results, maybe developing the AGDISP model or model presented by Seredyn [26]

\section{REFERENCES}

[1] Ashley H., Landahl M.T. 1965. Aerodynamics of Wing and Bodies .Reading, Addison-Wesley Publishing Co.

[2] Atias M., Weihs D., 1984. Motion of Aircraft Trailing Vortices Near the Ground. Journal of Aircraft. 21 (10): p. 783-786.

[3] Bache D.H., Sayer W.J.D., 1975. Transport of Aerial Spray. A Model of Aerial Dispersion. Agricultural Meteorology V. (15): p. 257-271. 
[4] Beyer E.M., 1991. Crop Protection Meeting the Challenge. Proceeding Brighton Crop Protection Conference, Weeds. 18-21 November, Brighton: p. 3-22.

[5] Bilianin A.J., Teske M.E., Barry J.W., Ekblad R.B., 1989. The Aircraft Spray Dispersion Model. Code Development and Experimental Validation. AGDISP. ASAE, V.32 (1): p. 327-334

[6] Boothroyd R.G., 1971. Flowing Gas-Solid Suspensions. London, Chapman and Hall.

[7] Bragg M.B., 1986. A Numerical Simulation of the Dispersal of Liquids from Aircraft. Transaction of the ASAE,V.29: p.10-15.

[8] Csanady G.T., 1973. Turbulent Diffusion in the Environment. D. Reidel Publishing Company. Dordrecht-Boston.

[9] Derevianko V.S., 1974. Vlijanie aerodynamiczeskich vozmuscenii na procesy aviacionnogo opylivanija i opryskivanija. Transport, Moskwa.

[10] Elliot J.G., Wilson B.J., (Editors). 1983. The Influence of Weather on the Efficiency and Safety of Pesticide Application. Occ. Publ. No.3 BCPC. Rand D. Council.

[11] ESDU No. 72026., 1972. Characteristics of the Wind Speed in the Lower of the Atmosphere Near the Ground: Strong Winds (Neutral Atmosphere). London.

[12] Harvey J.K., Perry F.J., 1971. Flow Field Produced by Trailing Vortices in the Vicinity of Ground. AIAA Journal, 9(8): p. 1659-1660.

[13] Leonard A., 1980. Vortex Methods for Slow Simulation. Journal of Computational Physics. 37: p. 289-335.

[14] Kamiński S., 1970. Analiza parametrów charakteryzujących rozpylanie ciektych środków ochrony roślin. Sprawozdanie 4.31.15. Instytut Lotnictwa, Warszawa.

[15] Kaul P., Meyer E., Gebauer S., 1995. Direkte abtrift von Pflanzenschutzmitteln-Flugzeug Nachrichtenbl. Deut. Pflanzenschutzd. 47(2): p. 36-44.

[16] Miranda L.R., Elliot R.D., Baker W.M., 1977. A Generalized Vortex Lattice Method for Subsonic and Supersonic Flow Applications. NASA CR 2865.

[17] Moore D.W., 1974. A Numerical Study of the Roll-up of a Finite Vortex Sheet. Journal of Fluid Mechanics 63(2): p. 225-235.

[18] Pietruszka J., Rowiński R.S., 2004. Computer Simulation of Aerial Spraying. Annual Review of Agricultural Engineering. 3(1): p.125-140.

[19] Ranz W.E., Marschall W.R., 1952. Evaporation from Drops. Chemical Engineering Progress. 48(3): 141-146, 48(4): p.173-180.

[20] Reed W.H., 1954. An Analytical Study of the Effectof Airplane Wake on the Lateral Dispersion of Aerial Sprays. NACA Report 1196.

[21] Rowiński R.S., 1993. Problems of Spray Drift in Plant Protection Using Aviation Techniques. Acta Acad. Agricult. Techn. Olst., Aed et 16: p. 171-195.

[22] Rowiński R.S., 2009. Zabiegi lotnicze w ochronie lasu. (praca pod red. Prof. B. Głowackiej). Wyd. Centrum Informacyjne Lasów Państwowych. Warszawa: p. 9-48.

[23] Rowiński R.S., Ferenc M., 2000. Some Problems Concerned with the Theory of Drift. Annual Review of Agricultural Engineering. 2(1): p. 148-156.

[24] Rowiński R.S., Wodecka C., Jumrych M., 1985. Metodyka badań Rolniczych Statków Powietrznych. Wydawnictwo. ART Olsztyn. Olsztyn.

[25] Seredyn T., Rowiński R., 2014. Experimental Investigations of a drifting Cloud of Droplets Dispersed from Aircrafts. Archive of Mechanical Engineering V. LXI. Nr. 3. p. 393-407. 
[26] Seredyn T. 2017. Weryfikacja formut matematycznych opisujacych proces ruchu kropel rozprzestrzenianych ze statku powietrznego. Wyd. Instytut Lotnictwa. Warszawa (Rozprawa doktorska).

[27] Soo S.L., 1971. Gidrodinamika mnogofaznych system. Izdatielstwo Mir. Moskawa. (Russian translation).

[28] Slade D.H., 1966. Summary Measurements of Dispersion from Quasi Instantaneous Sources. Nuclear Safety $7(2)$.

[29] Stenke W.E., Yates W.E., 1988. Modifying Gaussian Models to Obtain Improved Drift Prediction. Agricultural Engineering Department, University of California, Davis.

[30] Teske M.E, Thistle H.W., Londergan R.J. 2011. Modification of Droplets Evaporation in the Symulation of Fine Droplet Motion using AGDISP. Tran. of ASAE 54(2) p. 417-421.

[31] Teske M.E., Thistle H.W., Schou W.C., Miller P.C.H., Strager J.M., Richardson B., Butler E.M.C., Barry J.W., Twardus D.B., Thompson D.G., 2011. A Review of Computer Models for pesticide Deposition Prediction. Trans. ASAE 54(3): p. 789-801.

[32] Trayford R.S., Welch L.W., 1977. Aerial Spraying.: A Simulation of Factors Influencing the Distributionand Recovery of Liquid Droplets. Journal of Agricultural Engineering Research, Vol. 22: p. 183-196.

[33] Wickens R.H., 1977. Calculation of Wake Vortex Trajectories for Low Flying Spraying 2 Aircraft. National Aero Report LTR-LA-215 Nat. Res. Council. Canada.

\section{Figures}

Fig. 1. Model the Gaussian distribution

Fig. 2. The influence of evaporation on mass distribution. $h=5 \mathrm{~m}, \mathrm{~W}=3 \mathrm{dm}^{3} / \mathrm{s}, \mathrm{do}=80 \mu \mathrm{m}, \mathrm{V}_{\mathrm{w}}=3.5 \mathrm{~m} / \mathrm{s}$, $\mathrm{V}_{\mathrm{r}}=33.3 \mathrm{~m} / \mathrm{s}$

Fig. 3. Auxiliary plane $\prod$ for determining deformations of the vortex wake behind aircraft

Fig. 4. Propeller wake

Fig. 5. Cross-section of vortex wake behind the wing trailing edge

Fig. 6.Trajectories of water droplets

Fig. 7. Lateral distribution of nigrosine in $1 \%$ aqueous solution determined and theoretically [18], on the method proposed by [32] and experimentally

Fig. 8. The measurement line: 1 - measurement line, 2 - flight path, 3 - mass sampling sites, 4 - droplet sampling sites, 5 - masts, 6 - weather control station, 7 - camera, 8 - markers [21]

Fig.9. Comparison of theoretical and experimental results. $W=7.35 \mathrm{dm}^{3} / \mathrm{s}, \mathrm{h}=4.5 \mathrm{~m}, \mathrm{Vw}=4.5 \mathrm{~m} / \mathrm{s}$, $\mathrm{I}=0.1 .[21]$ 